\title{
Impact of Management Contracting on Employees' Commitment (A Case Study In Ethiotelecom)
}

\author{
Dawit Tekletsadik
}

\begin{abstract}
In this study the researcher investigates the impact of the management contracting and transformation of the ETC to ET on the commitment of the employees, the new managerial practices which influence the level of commitment of the employees negatively or positively. The study used different statistical sampling stages which include convenient sampling, judgmental sampling, stratified sampling and simple random sampling step by step, which enabled the researcher to withdraw 350 samples from the target population with the help of scientific sample determination formula. From the distributed, 343 questions were fully filled and taken as a relevant questionnaire for analysis. In analyzing the findings the researcher used descriptive statistics and multiple regressions analysis. The researcher found that the transformation of the management of ETC to ET brought a high positive effect on the affective and normative side of the employees' commitment; and a moderate effect on the continuance commitment of the employees; which averagely found a high effect. The managerial practices which positively and significantly affect the achieved commitment include the compensation, career development, the team spirit and work cooperation, and work environment and conditions. However the relation with management and the job security are found to have negative effect. The study recommends that the organization should have to give a due attention to link the employees' affective and normative commitment with the continuance commitment to reap the full benefit of the transformation. In addition it should have to revise the managerial practices with the problematic variables which include mainly relation with management and the job security.
\end{abstract}

Keywords: Employees' Commitment, Factors affecting commitment, Ethiopian Telecommunications Corporation, Ethio-Telecom

DOI: $10.7176 / \mathrm{EJBM} / 12-1-01$

Publication date: January $31^{\text {st }} 2020$

\section{Introduction}

The concept of outsourcing extends from the make-or-buy which is concerned with the transfer of activities and/or functions that have been performed internally to an external provider (Domberger, 1998). For this study, outsourcing is defined as an outcome of the total organizational management contracting that was formerly part of the organization and that now is part of another organization function and whose relationship is bounded by a contract.

Many Telecom operators in sub-Saharan African countries are currently witnessing job outsourcing initiatives to certain management services providers, where work, responsibilities, decision rights are transferred to an external expert entity that may be located within or outside the country. This initiative in recent times is generating much concern to operators and stakeholders. While the management of telecom sees this from the commercial perspective, others, especially the local staff and concerned individuals, are considering it as an initiative that will render them jobless and threaten their opportunity to become experts in the telecom field (Esonwune, 2010).

According to ET (2011) to become a world class service provider, the company has transferred itself with new brand name and brad image to managing business by caring out management contract with France telecom. France telecom branded as orange is a well known multinational telecom operator in the world which comprises telecom consultants and practitioners group known as soferecom dedicated for international service only. The company has reduced its employees from twelve thousand eight hundred in ETC to eight thousand five hundred fifty in ET, during the transformation. As per the company, one of the objectives of the management contracting with France telecom is to create well committed and efficient man power by avoiding the existing inefficient working culture. During ETC, employees' commitment was not measured and there is no any information that shows the trend of employee commitment from time to time. As a result, the researcher measured the employees' perception about their commitment before and after the management contract.

However different studies come with divers' findings with regard the effect of out sourcing in general and management contracting in particular on the industrialization of employees' attitude. A study made on the pros and cons of management service out sourcing in sub-Saharan countries found that while staffs at lower management positions are opposed to the strategy of out sourcing the Managed Services citing increased unemployment and diminished competency development as their major concern (Esonwune, 2010). Broedner et al. (2009) found that management outsourcing have a negative effect on labor productivity. On the contrary; other study indicates that strategic management outsourcing capability achieve success through effectiveness of operation and enhances employees' performance through creating industrialized attitude. (Khwanruedee et al., 2010). Telecom providers are re-organizing their structures and their portfolios of products and services with the 
aim of increasing revenues by looking for new opportunities and optimize operative costs as well as dedicated investment to create committed employees (Bramson-Boudreau, 2010).

The objective of this study was to assess the impact of management contracting on the commitment of ET employees using the commitment measures i.e. affective, continuance and normative.

\section{Literature Review}

As per the model developed by Meyer and Allen (1997) the three components of organizational Commitment, are affective, continuance and normative commitment. Meyer and Allen (1997) described that, the first component of organizational commitment which is Affective commitment (AC) focuses on emotional attachment and organizational involvement and deals with desires or wants ('I want my job'), and continuance commitment (CC) involves the perceived cost associated with leaving ('I need my job') where as normative commitment (NC) implies a sense of obligation to remain with the organization ('I ought to keep my job'. Normative commitment is the least understood component of commitment, and several researchers have suggested that this component may be multifaceted (Meyer \& Allen). More specifically, normative commitment develops as a means of socialization from both culture and the organization (Meyer \& Allen). Meyer and Allen discussed the differences that may exist in the way an employee experiences normative commitment due to these individual differences (i.e., culture). For example, normative commitment may have a greater influence on employee outcomes and well being within a collectivist culture as compared to an individualist culture due to the implied obligations inherent within collectivist cultures (Clugston, Howell \&Dorfman, 2000).

According to Richers (1985) there are different levels of organizational commitment which are related to organizational commitment. Below depicts the levels of commitment when it is increasing and when it is decreasing. Employee's level of commitment may move from a low level to a moderate level and continue to develop to a higher level of commitment or to an opposite direction the commitment level may go down from a high level of commitment to moderate and lower level of commitment

Randall (1990) has described that there are a variety of factors that affect organizational commitment. The factors include job-related factors (such as turnover, absenteeism, job effort, job role and performance or visa versa); employment opportunities (calculating the risks of remaining and leaving); personal characteristics (such as age, years of service and gender); positive relationships; organizational structure; and management style.

Taking the above review in to consideration, the researcher developed the following conceptual framework of, The HRM polices and strategies of a given organization are expected to be sources of different mind perceptions to its employees which include perceived self worth, perceived cost of loss, and perceived need to reciprocate. These perceptions are the great sources of employee commitments to their organization which are going to be classified as affective, continuance and normative commitments respectively.

As the result of these policies and strategies the affective, continuance and normative commitments of employees can be negative, neutral, or positive. These negative, neutral, or positive attitudes of commitment are created due to different causative factors which in turn are created due to the HRM policies and practices. Now the negative, neutral, or positive attitudinal commitments of employees are created through the evaluation of the different factors which include job-related factors; employment opportunities; personal characteristics; positive relationships; organizational structure; and management style.

\section{Figure 1. Conceptual Framework of the study}

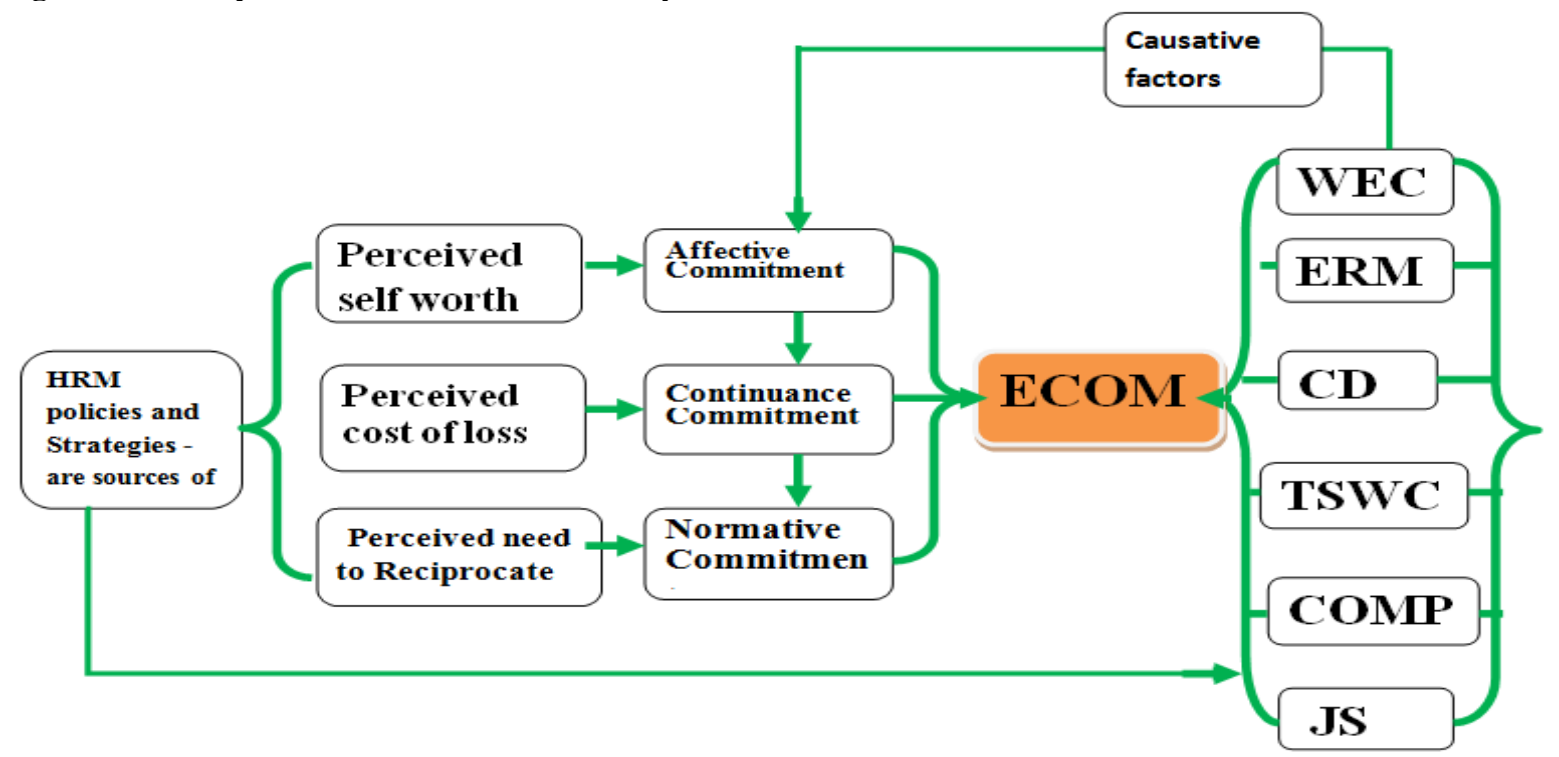




\section{Methodologies}

\section{Research Strategies and Designs}

The research strategy which was adopted for this research was basically both qualitative and quantitative approach. The research design that the researcher used for this research is Descriptive Survey Design which entails the collection of data on more than one case (usually quite a lot more than one) within the given study period.

The researcher used both none probability and probability sampling techniques which was employed at four stage sampling techniques. First, a convenience sampling was used to select the study area. Accordingly, Adama Branch and Addis Abeba Head Office Area were selected as these areas were easy to access to the employees and gather the required information through the designed data collection strategies. Second; a purposive sampling technique was employed to identify the target population. The target population which was selected for this study is current employees of ET who are employed not later than 2009. Third a stratified sampling technique is used. The nature of the employees of the ET is classified in to three based on their job field. These are, Network, Commercial and support. To have a representative of all these categories, the target population is grouped in to three main strata (i.e. Network' stratum, commercial stratum and support stratum). Then fourth, within each stratum, a simple random sampling technique mainly a lottery method is used to draw the individual samples with equitable representation of each stratum. Then using the mathematical formula developed by Yamane (1976), and a margin of error $5 \%$ a sample size of 382 were used for the study.

In order to attain the so far stated objectives the researcher employed both qualitative and quantitative data types. A primary data sources is used in order to gather these qualitative and quantitative data through a structured five point likert's questionnaire. For breaking the range distance in measuring the variables are computed by the formula adopted from Vichea (2005);

$\frac{(n-1)}{n}=\frac{(5-1)}{5}=\frac{4}{5}=0.8$, where $\mathrm{n}=$ numbers of rates in each the questionnaire

Meaning mean value of the variables falling within

$\checkmark$ 4.20-5.00 are going to be taken as the most important or the most problem level

$\checkmark$ 3.40-4.19 are going to be taken as the high important or the high problem level

$\checkmark$ 2.60-3.39 are going to be taken as the medium important or the medium problem level

$\checkmark$ 1.80-2.59 are going to be taken as the less important or the less problem level

$\checkmark$ 1.00-1.79 are going to be taken as the least important or the less problem level

\section{Model specification}

A model was specified to determine the influencing factors of employees' commitment to their organization. The dependent variable takes the average value of the three commitment variables i.e. the Affective commitment (with 8 items), Continuance Commitment (with 6 items), and Normative Commitment (with 6 items) which the researcher takes the average composed of 20 items score value.

The independent variables consists six main variables which include Working Environment and Conditions (WEC, with 6 items), Employees' Relationship with Management (ERM with 4 items), Career Development (CD, with 6 items), Team Sprit and Work Cooperation (TSWC, with 5 items), Compensation (COMP, with 5 items), Job Security (JS, with 6 items). Each independent variable takes the average of the items under it.

Then taking these dependent and independent variables into consideration the following mathematical model is developed to create the relation between them.

$\mathrm{p}_{i}=\frac{e^{\mathrm{Y}_{i}}}{1+e^{\mathrm{Y}_{i}}}$ The mathematical formula was adopted from (Gujarati, 2004).

Where, $\mathrm{p}_{i}$ is the probability an outcome, in our case the probability that a commitment of employees will be affected, $e$ is the natural number and $Y_{i}$ is the outcome equation for the commitment of employees to their organization, i.e. $\mathrm{Y}_{i}=\beta_{0}+\beta_{1} X_{1}+\beta_{i} \mathrm{X} \quad \mathrm{i}$

$i=1,2,3,---, \mathrm{n}$

$\beta_{0}=$ intercept

$\beta_{1}=$ regression coefficients to be estimated

$\mathrm{X}{ }_{\mathrm{i}}=$ independent variables that determine employees' commitment

Now more specific to this study, the model was specified as follows

Where

$E C O M=f(W E C$, ERM, CD, TSWC, COMP, JS + other

$$
E C O M=\beta_{0}+\beta_{1} W E C+\beta_{2} \text { ERM }+\beta_{3} \text { CD }+\beta_{4} \text { TSWC }+\beta_{5} \text { COMP }+\beta_{6} \mathrm{JS}+\epsilon
$$

ECOM=Employees' commitment,

WEC $=$ Working Environment and Conditions,

ERM=Employees' Relationship with Management

$\mathrm{CD}=$ Career Development

TSWC $=$ Team Sprit and Work Cooperation,

$\mathrm{COMP}=$ Compensation 
$\mathrm{JS}=\mathrm{Job}$ Security

$\epsilon=$ error term which stands for other variables which affect the dependent variable outside the above variables

\section{Results and Discussion}

To undertake this study the researchers distributed 382 questionnaires to the potential respondents, of which 368 questionnaires have been collected. However, only 343 questionnaires were properly filled with the necessary data that the study demanded and relevant for analysis. Therefore this study used 343 respondents for analysis, and the response rate was above $90 \%$. Thus, the response rate was considered as well representative to undertake this study. Of the total $81.1 \%$ of respondents are male and $18.19 \%$ are females. This percentage of sample distribution for sex distribution is equivalent with the actual percentage of population distribution for sex which is $80 \%$ male and $20 \%$. Most of respondents fall in the age category of 31 to 40 years old which accounts $58.7 \%$; and the rest are found in the age category of less than 30 years old, 41 up to 50 years old and above 50 years old with a percentage of $25.2 \%$, $12.6 \%$ and $3.5 \%$ respectively. The main reason for the respondents to fall in the age category of 31 to 40 years old is that due to the fact that the target population for sampling was required at least to have six year work experience.

According to their job family is $44.1 \%, 15.4 \%$ and $40.6 \%$ is from Network, Commercial and Support respectively. According to their job level $76.2 \%, 20.3 \%$, and $3.5 \%$ are found to be employees with job level C, D, and $\mathrm{E}$ respectively. Of them $23.8 \%$ found to be at supervisory and $76.2 \%$ at non supervisory level.

\section{Reliability Analysis}

In order to undertake his study the researcher adopted and modified the Model questionnaire developed by Meyer and Allen (1997), and organized them with modification in three main contents. In addition to that the researcher adds questionnaire to analyze the influencing factors to the resultant commitment. Without including the questions for preliminary information, therefore, the main content of the questionnaire was organized into four main categories with 30 question items.

Table 1: Reliability Test result

\begin{tabular}{|l|ll|}
\hline Elements & Cronbach's Alpha & Number of Items \\
\hline Affective Commitment & $\mathbf{. 8 0 1}$ & $\mathbf{8}$ \\
Continuity Commitment & .713 & 6 \\
Normative Commitment & .737 & 6 \\
Influencing Factors & .844 & 32 \\
\hline
\end{tabular}

Source: Source: own construction from a survey questionnaire, $2017 \quad n=343$

Before passing to the main analysis, the researchers should assured that the questions are within the required reliability standards. Then as clearly shown from the table 4.3 , the reliability test result found to be $\mathbf{. 8 0 1}, \mathbf{. 7 1 3}, \mathbf{. 7 3 7}$ and $\mathbf{8 4 4}$ for Affective Commitment, Continuity Commitment, Normative Commitment, and Influencing Factors. From this we can conclude that Cronbach's alpha for Continuity Commitment and Normative Commitment are found to be with the acceptable and Affective Commitment and Influencing Factors are gain a high reliability. Therefore the data is reliable to proceed or analysis.

The other reliability test in the reliability analysis is the Multicollinearity test. Multicollinearity refers to high correlations among the independent variables whereas singularity is when there is prefect correlation among the independent variables. According to Dillon and Goldstein (1984), multicollinearity will result in highly unstable regression coefficients, and as such, the independent variable should have a low multicollinearity among them. The Variance Inflation Factor (VIF) measures this and if the tolerance values is less than 10 for all factors, then this means that the study is safe from multicollinearity problems (Hair et al, 2006). For all the independent variables, the tolerance values were found to be less than 10 for all factors in the range of 0.613 to 0.714 . Therefore, this means that the study is safe from multicollinearity problems.

Normality, linearity, homoscedasticity and independence of residuals can be determined using the residual scatterplots. According to Coakes and Steed, (2007), if the residual have a linear relationship with the predicted dependent variable score, then there is a linear relationship. The scatterplots and the residual plots were found to have fulfilled the above requirement.

\section{Evaluation of Commitment of Employees}

As per the model developers, Meyer and Allen (1997), the first component of organizational commitment is Affective Commitment which focuses on emotional attachment and organizational involvement and deals with desires or wants ('I want my job'). 
Table 2: Descriptive Statistics for Affective commitment of employees

\begin{tabular}{|c|c|c|c|c|c|c|}
\hline R/No & Item & Min* & Max** & Mean & $\begin{array}{l}\text { Std. } \\
\text { Deviation }\end{array}$ & Decision \\
\hline 1 & $\begin{array}{l}\text { To what extent you are happy to spend the rest of } \\
\text { your career with this organization ET in } \\
\text { comparing to ETC. }\end{array}$ & 1 & 5 & 3.78 & .945 & $\begin{array}{l}\text { High } \\
\text { Effect }\end{array}$ \\
\hline 2 & $\begin{array}{l}\text { To what extent do you feel that this organization's } \\
\text { (ET's) problems are your own problems as well in } \\
\text { comparing to ETC. }\end{array}$ & 1 & 5 & 3.59 & 1.044 & $\begin{array}{l}\text { High } \\
\text { Effect }\end{array}$ \\
\hline 3 & $\begin{array}{l}\text { To what extent do you feel a strong sense of } \\
\text { "belonging" to the ET as compared to ETC. }\end{array}$ & 1 & 5 & 3.68 & .939 & $\begin{array}{l}\text { High } \\
\text { Effect }\end{array}$ \\
\hline 4 & $\begin{array}{l}\text { To what extent do you feel that you are } \\
\text { "emotionally attached" to ET as compared to } \\
\text { ETC. }\end{array}$ & 1 & 5 & 3.57 & 1.004 & $\begin{array}{l}\text { High } \\
\text { Effect }\end{array}$ \\
\hline 5 & $\begin{array}{l}\text { To what extent do you feel at ET like "part of the } \\
\text { family" as compared to ETC. }\end{array}$ & 2 & 5 & 3.30 & .849 & $\begin{array}{l}\text { Moderate } \\
\text { Effect }\end{array}$ \\
\hline 6 & $\begin{array}{l}\text { To what extent do you feel that the ET has a great } \\
\text { deal of personal meaning for you as compared to } \\
\text { ETC. }\end{array}$ & 1 & 5 & 3.78 & .922 & $\begin{array}{l}\text { High } \\
\text { Effect }\end{array}$ \\
\hline 7 & $\begin{array}{l}\text { To what extent do you believe that employee's } \\
\text { roles and job goals are clearly defined in ET } \\
\text { compared to ETC. }\end{array}$ & 1 & 5 & 3.60 & 1.042 & $\begin{array}{l}\text { High } \\
\text { Effect }\end{array}$ \\
\hline 8 & $\begin{array}{l}\text { To what extent do you believe that management } \\
\text { support regarding employee's job performance in } \\
\text { ET is greater than in ETC. }\end{array}$ & 1 & 5 & 3.34 & 1.014 & $\begin{array}{l}\text { Moderate } \\
\text { Effect }\end{array}$ \\
\hline & Average & & & 3.62 & & $\begin{array}{l}\text { High } \\
\text { Effect }\end{array}$ \\
\hline
\end{tabular}

Source: Source: own construction from a survey questionnaire, 2017 n=343 *Minimum, **Maximum

Taking the information from Table 1 and the predefined our decision rule in to consideration; the new management system of ET as compared to ETC brought a high effect on the attitude of the employees to feel happy to spend the rest of your career with ET; to feel that the ET's problems as if their own problem; to feel a strong sense of "belonging" to the ET; to feel as a great deal of personal meaning for them, and to feel all their roles and goals are clear. In addition to that the new management system found to have a moderate effect on the employees to feel ET like "part of the family"; and to assume highjob performance. On a summed effect, the new management system has brought a high effect on affective commitment of employees of ET as compared to ETC with a mean of 3.62. This is similar with the findings of(Wang, et al 2010; Liden et al. 2003; Coyle-Shapiro et al. 2006). From this we can conclude that employees of ET are highly interested with their job. This means they are highly interested to stay with this job. Taking the findings stated above the researcher is confident enough to conclude that the affective commitment of employees of ET is higher than that of ETC.

The second dimension of the tri-dimensional model of organizational commitment is continuance commitment. Meyer and Allen (1997,) define continuance commitment as "awareness of the costs associated with leaving the organization". It deals with the commitment of an employee to further continue work in the organization due to the inter-employee relationships and associations and other non-transferable funds and investments like allowance and retirement fund or retirement remuneration. It is found that, they moderately think that; their life would be disrupted if they decided to leave ET; feel that now they have too few options to consider leaving ET; consider them self that, if they had not already put so much of themselves into ET they might consider working elsewhere; agree that for them the negative consequences of leaving ET would be the scarcity of available alternatives. 
Table 3: Descriptive Statistics Continuity commitment of employees

\begin{tabular}{|c|c|c|c|c|c|c|}
\hline R/No & Item & Min* & $\operatorname{Max} * *$ & Mean & $\begin{array}{l}\text { Std. } \\
\text { Deviation }\end{array}$ & Decision \\
\hline 1 & $\begin{array}{l}\text { To what extent you think that right now, } \\
\text { staying with ET is a matter of necessity as } \\
\text { much as you desire as compared to ETC. }\end{array}$ & 1 & 5 & 3.64 & .900 & High Effect \\
\hline 2 & $\begin{array}{l}\text { To what extent do you think that it would be } \\
\text { very hard for you to leave ET right now, even } \\
\text { if you wanted to, as compared to ETC. }\end{array}$ & 1 & 5 & 3.45 & 1.053 & High Effect \\
\hline 3 & $\begin{array}{l}\text { To what extent do you think that your life } \\
\text { would be disrupted if you decided to leave ET } \\
\text { now as compared to ETC }\end{array}$ & 1 & 5 & 3.13 & 1.020 & $\begin{array}{l}\text { Moderate } \\
\text { Effect }\end{array}$ \\
\hline 4 & $\begin{array}{l}\text { To what extent you feel that now you have too } \\
\text { few options to consider leaving ET as } \\
\text { compared to ETC }\end{array}$ & 1 & 5 & 3.28 & .883 & $\begin{array}{l}\text { Moderate } \\
\text { Effect }\end{array}$ \\
\hline 5 & $\begin{array}{l}\text { To what extent do you consider yourself that, } \\
\text { if you had not already put so much of yourself } \\
\text { into ET, you might consider working } \\
\text { elsewhere as compared to ETC. }\end{array}$ & 1 & 5 & 3.31 & .883 & $\begin{array}{l}\text { Moderate } \\
\text { Effect }\end{array}$ \\
\hline 6 & $\begin{array}{l}\text { To what extent do you agree that for you the } \\
\text { negative consequences of leaving ET would be } \\
\text { the scarcity of available alternatives as } \\
\text { compared to ETC. }\end{array}$ & 1 & 5 & 3.08 & .908 & $\begin{array}{l}\text { Moderate } \\
\text { Effect }\end{array}$ \\
\hline & Average & & & 3.32 & & $\begin{array}{l}\text { Moderate } \\
\text { Effect }\end{array}$ \\
\hline
\end{tabular}

Source: Source: own construction from a survey questionnaire, $2017 \quad \mathrm{n}=343 *$ Minimum, **Maximum

Cumulatively, unlike to the finding on affective commitment which is found to be high with a mean value of 3.62; the new management system has brought a moderate effect on continuance commitment of employees of ET as compared to ETC with a mean value of 3.32. From this we can conclude that employees of ET are highly interested with their job.

The last dimension of the organizational commitment is normative commitment, "a feeling of obligation to continue employment". Studies indicate that normative commitment of employees is highly affected by the management system of the employer organizations. Employees' normative commitment is optimistically connected with higher level of place of work performance and management system of companies (Sarah, et al. 2011). Normative commitment relaxes on employees' compulsory feelings towards management; people stay because they think an obligation to perform so (Ahmadi\&Avajian, 2011).

Table 4: Descriptive Statistics Continuity commitment of employees

\begin{tabular}{|c|c|c|c|c|c|c|}
\hline R.No & Item & Min* & $\operatorname{Max} * *$ & Mean & $\begin{array}{l}\text { Std. } \\
\text { Deviation }\end{array}$ & Decision \\
\hline 1 & $\begin{array}{l}\text { To what extent do you feel that you have any } \\
\text { obligation to remain with ET as compared with } \\
\text { ETC }\end{array}$ & 1 & 5 & 3.43 & 1.045 & $\begin{array}{l}\text { High } \\
\text { Effect }\end{array}$ \\
\hline 2 & $\begin{array}{l}\text { To what extent do you feel it would be right to } \\
\text { leave ET, if you found a better advantage, as } \\
\text { compared to ETC }\end{array}$ & 1 & 5 & 3.84 & .901 & $\begin{array}{l}\text { High } \\
\text { Effect }\end{array}$ \\
\hline 3 & $\begin{array}{l}\text { To what extent would you feel guilty if you left } \\
\text { ET as compared to ETC }\end{array}$ & 1 & 5 & 3.05 & 1.090 & $\begin{array}{l}\text { Moderate } \\
\text { Effect }\end{array}$ \\
\hline 4 & $\begin{array}{l}\text { To what extent do you think that ET deserves } \\
\text { your loyalty as compared to ETC. }\end{array}$ & 1 & 5 & 3.59 & .929 & $\begin{array}{l}\text { High } \\
\text { Effect }\end{array}$ \\
\hline 5 & $\begin{array}{l}\text { To what extent you perceive that you will not } \\
\text { leave ET now believing that you have a sense of } \\
\text { obligation to the people in it as compared to ETC. }\end{array}$ & 1 & 5 & 3.55 & .955 & $\begin{array}{l}\text { High } \\
\text { Effect }\end{array}$ \\
\hline 6 & $\begin{array}{l}\text { To what extent you owe a great deal to ET as } \\
\text { compared to ETC. }\end{array}$ & 1 & 5 & 3.70 & .912 & $\begin{array}{l}\text { High } \\
\text { Effect }\end{array}$ \\
\hline & Average & & & 3.53 & & $\begin{array}{l}\text { High } \\
\text { Effect }\end{array}$ \\
\hline
\end{tabular}

Source: Source: own construction from a survey questionnaire, 2017 n=343*Minimum, **Maximum 
In summative effect, similar to the finding on affective commitment the new management system has brought a high effect on normative commitment of employees of ET as compared to ETC with a mean value of 3.53. From this we can conclude that employees of ET are developing a great sense of obligation and belongingness to continue their employment with ET as a result of the new management system.

Table 5: Descriptive Statistics of Overall Attitudinal commitment of employees

\begin{tabular}{llll} 
R.No & Item & Average & Decision \\
\hline $\mathbf{1}$ & Affective Commitment & $\mathbf{3 . 6 2}$ & High Effect \\
$\mathbf{2}$ & Continuity commitment & $\mathbf{3 . 3 2}$ & Moderate Effect \\
$\mathbf{3}$ & Normative Commitment & $\mathbf{3 . 5 3}$ & High Effect \\
\hline & Average & $\mathbf{3 . 4 9}$ & High Effect \\
\hline
\end{tabular}

Source: Source: own construction from a survey questionnaire, $2017 \quad n=343$

Taking both the summarized information from Table 5 and the predefined decision rule adopted by the researchers in to consideration; it is found that the new management system of ET as compared to ETC brought a high effect on the affective commitment and normative commitment attitudinal side of the employees with a mean value of 3.62 and 3.53 respectively; and brought a moderate effect on the continuance commitment side of the employees with a mean of 3.32. However, the good news here is it is found that the average effect of the transformation of the management system of ETC to ET brought a high positive effect on the attitude of the employees with a mean value of 3.49 .

From these findings, now, we are confident enough to conclude that the new management of ET let the employees they highly love their job and they greatly develop a sense of mental obligation to continue with ET. Then ET is now right to take this as a one success. However, there is a yellow light which can disturb the success. The employees love to their job and their sense of mental obligation to continue with ET is not well connected with awareness of "the costs associated with leaving the organization". The commitment of the employees to further continue work in the organization is not well connected with the inter-employee relationships and associations and other non-transferable funds and investments like allowance and retirement fund or retirement remuneration. This means they still perceive that there is at least a parallel and/or better opportunity in the environment availed to them. Such thinking can have a negative influence on the attitude of the employees not to fully commit themselves to their organization, ET.

\section{The Link between Employee Characteristic and Commitment}

Contradicting results across researches have been found in between the different characteristics of the employees and organizational commitment linkage. Age and tenure were shown to have a strongly significant relationship with the organizational commitment and its forms (Pathardikar and Sahu, 2011). As workers stay with an organization increases, his level of commitment is also likely to go up (Ahmad and Bakar, 2003; Jayasingam\& Yong, 2013). Higher level managers exhibit higher organizational commitment levels as compared to their lower level counterparts in the organization (Natarajan\& Nagar 2011). On the contrary other studies revealed; that employees belonging to the lower age group had a lower level of affective commitment (Su et al, 2009); demographic factors did not have a strong relationship with affective commitment, with only tenure showing a significant relation with employees' affective commitment level (Feryal Khan and SohailZafar, 2013). Having these divers' findings in to consideration, the researcher evaluates if there is any difference to the commitment of employees linked to their characteristics.

As it is shown from the Table 6; it is found that there is no difference in commitments of employees associated with their sex, job family they have being a supervisor or supervisee which seems similar with the finding of Feryal Khan and SohailZafar (2013). However it is found that, the younger employees are lesser committed than the older ones. Unlike to the other age categories in which their commitment is found to be high, the age category under 30 years old found to have a moderate commitment. In addition to that, it is found that as age increases the level of employee commitment increases. This is finding is parallel with studies of Pathardikar and Sahu (2011); which found that older workers are expected to have higher affective commitment than younger employees. This might be due to the fact that employees in the younger age bracket may not develop emotional attachment to the organization and might show lesser readiness to commit to an organization for a longer because they are always in search of better organizations; and the older employees are committed due to various reasons including higher satisfaction with their jobs, better positions etc. 
Table 6: Descriptive Statistics relating characteristics and commitment of employees

\begin{tabular}{|c|c|c|c|c|c|c|}
\hline Item & Categories & $\begin{array}{l}\text { Affective } \\
\text { Commitment }\end{array}$ & $\begin{array}{l}\text { Continuance } \\
\text { Commitment }\end{array}$ & $\begin{array}{l}\text { Normative } \\
\text { Commitment }\end{array}$ & Average & Decision \\
\hline \multirow{2}{*}{$\begin{array}{l}\text { Sex of } \\
\text { Respondent }\end{array}$} & Male & 3.63 & 3.38 & 3.5 & 3.50 & High Effect \\
\hline & Female & 3.55 & 3.34 & 3.54 & 3.47 & High Effect \\
\hline \multirow{4}{*}{$\begin{array}{l}\text { Age of } \\
\text { Respondents }\end{array}$} & under 30 & 3.67 & 2.73 & 3.4 & 3.26 & Mod. Effect \\
\hline & 31 up to 40 & 3.56 & 3.32 & 3.52 & 3.46 & High Effect \\
\hline & 41 up to 50 & 3.85 & 3.46 & 3.16 & 3.49 & High Effect \\
\hline & above 50 & 3.63 & 3.71 & 3.72 & 3.68 & High Effect \\
\hline \multirow{3}{*}{$\begin{array}{l}\text { Job Family of } \\
\text { Respondents }\end{array}$} & Network & 3.49 & 3.35 & 3.55 & 3.46 & High Effect \\
\hline & Commercial & 3.72 & 3.49 & 3.36 & 3.52 & High Effect \\
\hline & Support & 3.7 & 3.34 & 3.5 & 3.51 & High Effect \\
\hline \multirow{3}{*}{$\begin{array}{l}\text { Job Level of } \\
\text { Respondent }\end{array}$} & $\mathrm{C}$ & 3.63 & 3.35 & 3.53 & 3.50 & High Effect \\
\hline & $\mathrm{D}$ & 2.78 & 3.14 & 2.7 & 2.87 & Mod. Effect \\
\hline & $\mathrm{E}$ & 3.756 & 3.47 & 3.56 & 3.59 & High Effect \\
\hline \multirow{2}{*}{$\begin{array}{l}\text { Respondents } \\
\text { supervise } \\
\text { others...? }\end{array}$} & Yes & 3.68 & 3.47 & 3.4 & 3.51 & High Effect \\
\hline & No & 3.58 & 3.33 & 3.53 & 3.48 & High Effect \\
\hline \multirow{4}{*}{$\begin{array}{l}\text { Highest level } \\
\text { of Education } \\
\text { of Responden }\end{array}$} & Certificate & 2.25 & 3.16 & 3.58 & 2.99 & Mod. Effect \\
\hline & Diploma & 3.62 & 3.3 & 3.67 & 3.53 & High Effect \\
\hline & First Degree & 3.65 & 3.32 & 3.48 & 3.48 & High Effect \\
\hline & $>=$ Masters & 2.79 & 2.65 & 2.33 & 2.59 & Low Effect \\
\hline \multirow{5}{*}{$\begin{array}{l}\text { Work } \\
\text { Experience }\end{array}$} & $6 \leq X \leq 10$ & 3.61 & 3.28 & 3.58 & 3.49 & High Effect \\
\hline & $10<X \leq 15$ & 3.56 & 3.2 & 3.4 & 3.38 & Mod. Effect \\
\hline & $15<X \leq 20$ & 2.81 & 3.25 & 3.25 & 3.10 & Mod. Effect \\
\hline & $20<X \leq 25$ & 3.71 & 3.52 & 3.36 & 3.53 & High Effect \\
\hline & $X>25$ & 3.92 & 3.53 & 3.86 & 3.77 & High Effect \\
\hline
\end{tabular}

Source: own construction from a survey questionnaire, 2017 n=343; Mod. Effect=Moderate effect

The difference in job level is also found to have effect to the difference on employees' commitment. As it is shown that, employees who are found in the D job level which comprises the supervisors and specialists are found to have moderate level of commitment. However, the employees who are found in the job level of $\mathrm{C}$ who are employees of non supervisory level and the job level of $\mathrm{E}$ who are managerial positions are found to be highly committed. The finding on the job level C is parallel with the finding of Irving et al (1997) which stated that early job experiences play a significant role in developing higher commitment levels; and the finding on the job level of E is similar with the finding of Natarajan\& Nagar (2011) which underlined higher level managers exhibit higher organizational commitment levels as compared to their lower level counterparts in the organization.

There is a significant difference in the level of commitment in relation to the educational level they have. Employees who are Diploma Holders and First Degree Graduates are found to be highly committed. However employees with certificate are found to be moderately happy and employees with Masters Degree and above are found to be low committed. This might be due to the fact that the organizational structure of the organization is not welcoming to Certificate holders and accommodating positions for those who are with Masters Degree and above.

Employees with the first tenure group which is 6-10 years of experience and the last two tenure group which comprises a work experience of more than 20 years all appear to have a high commitment. However, the remaining two tenure group found in between these two which comprises the employees with the experience of 10.1-20 years, are found to have a moderate commitment. This might be due to the fact employees who work in an organization for somewhat elongated period in between becomes bored with what they have and starts for better jobs. This can reduce their commitment to their current organization. 
From the analysis of the linkage between employee characteristics and commitment there is one important point that the company should have to be aware of it. In analyzing the linkage between job level and employee commitment of the job levels $\mathrm{C}, \mathrm{D}$, and $\mathrm{E}$; the researcher found the employees with job level $\mathrm{D}$ is found lesser committed than the others. In analyzing the linkage between tenure and commitment, of the grouped five tenure level which include work years $6 \leq X \leq 10,10<X \leq 15,15<X \leq 20,20<X \leq 25$, and $X>25$ the researchers once again found that the employees with tenure found in the middle i.e. 10.1-20 are identified as less committed than the other extremes. Now these two have a great linkage which can loudly tell us there is a problem around the middle in which the company should have to dig out its cause and solve it.

\section{Factors Affecting Employees Organizational Commitment}

The dependent variable in this case is the Employees' Organizational Commitment (ECOM), which was measured by 20 items which were grouped in to the three employee commitment categories; Affective Commitment, Continuance Commitment, and Normative Commitment. Then the average of these three variables is taken and treated as one variable.

Table 7: correlation matrix for the variables affecting employees' commitment

$\begin{array}{llllllll} & \text { ECOM } & \text { WEC } & \text { ERM } & \text { CD } & \text { TSWC } & \text { COMP } & \text { JS } \\ \text { ECOM } & 1 & & & & & & \\ \text { WEC } & .481^{* *} & 1 & & & & \\ \text { ERM } & .333^{* *} & .549^{* *} & 1 & & & \\ \text { CD } & .719^{* *} & .352^{* *} & .287^{* *} & 1 & & \\ \text { TSWC } & .176^{*} & .150^{*} & -.055 & .139 & 1 & 1 \\ \text { COMP } & .750^{* *} & .404^{* *} & .250^{* *} & .293^{* *} & .017 & 177^{* *} & 1 \\ \text { JS } & .715^{* *} & .567^{* *} & .551^{* *} & .333^{* *} & .037 & .867^{* *}\end{array}$

**. Correlation is significant at the 0.01 level (2-tailed), *. Correlation is significant at the 0.05 level (2tailed), n=143 ECOM=Employees' commitment, WEC=Working Environment and Conditions, ERM=Employees' Relationship with Management , CD= Career Development , TSWC $=$ Team Sprit and Work Cooperation, COMP $=$ Compensation , JS=Job Security

Source: own construction from a survey questionnaire, $2017 \quad n=343$

The study incorporated six independent variables which comprises 32 items. These independent variables are Working Environment and Conditions (WEC), Employee Relationship with Management (ERM), Career Development (CD), Team Sprit and Work Cooperation (TSWC), Compensation (COMP), Job Security (JS). These independent variables are measured by the average value of the items incorporated in the variables of WEC, RWM, CD, TSWC, COMP, and JS which comprises 6, 4, 6, 5, 5 and 6 items respectively. The detailed analysis is in the subsequent sections.

Correlation test was conducted to verify existence of relationship between the independent variables i.e. WEC, ERM, CD, TSWC, COMP, and JS; and the dependent variable ECOM. The researcher found that, the variables Work environment and condition, Relation with Management, Career Development, Compensation, and Job Security shows a strong positive correlation coefficient of $0.481,0.333,0.719,0.750$ and 0.715 respectively with the employee commitment significant at $\mathrm{p} \leq 0.01$. With a slight difference from these, the variable Team Sprit and Work Cooperation shows a positive correlation coefficient of 0.176 significant at $\mathrm{p} \leq 0.05$.

According to Sekaran (2003), a 5-point Likert scale is an interval scale. Hence, the researcher used multiple regression analysis to analyze the data and test hypotheses. From the results of the multiple regression analysis, as shown in Table 4.8, the adjusted R-square is 0.832 which means that $83.2 \%$ variance is explained by the six independent variables, namely WEC, ERM,CD, TSWC, COMP, and JS; while the remaining $16.8 \%$ is not explained. ANOVA test results showed that the significance level is less than 0.01 indicating that the independent variables as a whole influence the employees' organizational commitment.

In the regression coefficients shown in the table 8 revealed that of the six independent variables, the four i.e. WEC, CD, TSWC, and COMP are found to be positively related to the dependent variable of ECOM; and two independent variables i.e. ERM and JS are negatively related to the dependent variable of ECOM. However, unlike those variables with a positive relation which are significant at $1 \%, 5 \%, 1 \%$ and $1 \%$ respectively; the variables which negatively related are found to be insignificant at $5 \%$. 
Table 8: Regression coefficients for the variables affecting employees' commitment

\begin{tabular}{|c|c|c|c|c|c|c|}
\hline \multicolumn{2}{|c|}{ Model } & \multicolumn{2}{|c|}{$\begin{array}{l}\text { Unstandardized } \\
\text { Coefficients }\end{array}$} & \multirow{2}{*}{$\begin{array}{l}\text { Standardized } \\
\text { Coefficients } \\
\text { Beta }\end{array}$} & \multirow[t]{2}{*}{$\mathbf{T}$} & \multirow[t]{2}{*}{ Sig. } \\
\hline & & B & Std. Error & & & \\
\hline \multirow[t]{7}{*}{1} & (Constant) & .455 & .160 & & 2.846 & .005 \\
\hline & WEC & .038 & .031 & .056 & 1.229 & .021 \\
\hline & ERM & -.012 & .033 & -.019 & -.370 & .712 \\
\hline & $\mathrm{CD}$ & .405 & .029 & .532 & 13.991 & .000 \\
\hline & TSWC & .011 & .028 & .014 & 1.398 & .010 \\
\hline & COMP & .407 & .066 & .513 & 6.160 & .000 \\
\hline & JS & -.058 & .077 & -.073 & -.747 & .457 \\
\hline
\end{tabular}

Dependent Variable: ECOM

R Square $=.839$;

Adjusted R Square $=0.832$;

Significance $\mathbf{F}=.0000$;

Source: own construction from a survey questionnaire, $2017 \quad \mathrm{n}=343$

The first independent variable considered for this study was the conduciveness of the Work Environment and Condition (WEC) created with the emergence of the new management of ET. It is found that the new management of ET's WEC has a strong positive effect with a coefficient of 0.038 on the employees' organizational commitment significant at $1 \%$. This indicates that a $1 \%$ increase in the level of conduciveness of the working environment and condition; at leads to $3.80 \%$ increase on the employees commitment. This finding is parallel with the findings of (Tung et al. 2014; and Muhammed et al. 2014), which states that the work environment and work condition has a strong positive effect on employees commitment to their organization. From this we can conclude that the new management of ET brings an improvement in the commitment of its employees by enhancing the conduciveness of the working environment and working conditions in the company.

The second and sixth variables discussed here in this study were the Relation with Management (ERM) and the Job Security (JS), which were expected that the new management system along with its new human resources management practices brought a new in kind of relationship within the managers and supervisors with their followers and also expected to develop a feeling of secured from losing their job; which in turn both were expected to have a significant positive effect on the employees' overall organizational commitment. But, as it is clearly shown from the table 4.8, though the new management of ET able to build a high level of organizational commitment, it is found that the existed ERM system and the feeling of JS has a negative effect with the development of the employees' organizational commitment at a coefficient of -0.012 and -0.077 respectively. However it is found that both are insignificant at 5\%. From this we can conclude that though the new management system of ET able to develop a high level of employees' organizational commitment; the researcher did not have an evidence to say that ET's designed employees' relation with their management and the feeling of job security build in the mind of the employees have its own contribution for the development the achieved level of commitment.

The third variable that the researcher considered to investigate in this study was the effect of the Career Development (CD) system established with ET to the employees' organizational commitment. The researcher found that the new management of ET's CD system has a strong positive effect with a coefficient of 0.405 on the employees' organizational commitment significant at $1 \%$. This indicates that a $1 \%$ increase in the level of CD; it leads to $40.5 \%$ increase on the employees commitment. This finding is different from the finding of Tung et al. (2014) which found a positive but insignificant at 5\%. However, it is parallel with the finding of Muhammed et al. (2014) a positive effect and significant 5\%. From this we can infer that the ETs career development programs have significant contribution to the development of the achieved employees' organizational commitment.

The fourth variable that the researcher considered to investigate in this study was the effect of the Team Sprit and Work Cooperation (TSWC) system established with ET to the achieved employees' organizational commitment. The researcher found that the new management of ET's TSWC system has a strong positive effect with a coefficient of 0.011 on the employees' organizational commitment significant at $1 \%$. This indicates that a $1 \%$ increase in the level of TSWC; it leads to $1.10 \%$ increase on the employees commitment. However this variable is the smallest positive contributor with $1.10 \%$ followed by WEC with $3.80 \%$ of effect for $1 \%$ increment in the variables. This finding is parallel with the finding of Tung et al. 2014; Muhammed et al. 2014) which found a positive effect and significant effect at 5\%. Taking these inputs in to consideration the researcher failed to accept the null hypothesis which states that the Team Sprit and Work Cooperation (TSWC) system established with ET do not have a positive significant effect on the ET's employees' organizational commitment. Therefore, the 
researcher can infer that the TSWC system of ET has a great contribution to the achieved employees' organizational commitment.

The last variable that the researcher considered to investigate in this study was the effect of the Compensation (COMP) system established with ET to the achieved employees' organizational commitment. The researcher found that the new management of ET's COMP system has a strong positive effect with a coefficient of 0.407 on the employees' organizational commitment significant at $1 \%$. This indicates that a $1 \%$ increase in the level of TSWC; it leads to $40.70 \%$ increase on the ET's employees commitment. This figure tells us that, the highest contributor to the achieved high level of employees' organizational commitment of ET is its compensation (COMP) system followed by the Career Development (CD), with an increase of $40.70 \%$ and $40.50 \%$ respectively in an increase of each variable by $1 \%$. This finding is a slight different from the finding of Tung et al. (2014) in which it found a positive but insignificant at 5\%. However, it is parallel with the finding of Muhammed et al. 2014) a positive effect and significant at 5\%. Taking these inputs in to consideration, now, the researcher is not confident to accept the null hypothesis. From this we can infer that the ETs compensation programs have significant contribution to the development of the achieved employees' organizational commitment in ET.

On a summed effect the researcher found a result which seems an incidence that lead us to group the six variables in three categories each comprises two variables; in which the researcher now interested to group them as variables with Low Effect (ERM and JS), Moderate Effect (TSWC and WEC); and High Effect (COMP and $\mathrm{CD})$ to their contributive effect on the achieved high level organizational commitment which given us the following final equation.

$$
\text { ECOM }=.455+.038 W E C-.012 \mathrm{ERM}+.405 \mathrm{CD}+.011 \mathrm{TSWC}+.407 \mathrm{COMP}-.058 \mathrm{JS}+\epsilon
$$

Even though they are insignificant with the pre stated margin; the employees Relation with Management (ERM) and the Job Security (JS) variables are found to have a negative effect. These two variables tells us that even though the average commitment level of ET is found to be high; the management system of ET did not designed a proper employees Relation with Management and Job Security development systems in a manner these two things also add-up other contribution so that the commitment level will go-up from high level to a very high level.

The Team Sprit and Work Cooperation (TSWC) and the Work Environment and Condition (WEC) have a moderate effect on the achieved high level of Commitment of the employees of ET to their organization. Though the net effect of these variables is positive and significant; their rate of response to the increment in commitment is not as high as that of COMP and CD variables. Therefore the management of ET is highly expected to improve its management practice in relation to these variables.

To the other side, the Compensation packages and the Career Development programs of the management of ET provide a significant contribution in the improvement of the commitment of Employees of ET. Therefore the management of ET needs a due care at least to keep the managerial practices of these variables at this pace and if possible to improve them.

\section{Summary and Conclusion}

$\checkmark$ As the employees of ET assumed themselves they are working in a better public organization, with a better pay and other benefit packages assured by the findings from the structured questionnaire and the inputs from the three focus group discussions; now the researcher is confident enough to conclude that the management of ET brought a affective commitment on its employees as compared that of ETC.

$\checkmark$ As compared to ETC employees of ET are highly interested to stay with their job. But the reason they want to stay with this organization is not because of fear of the costs associated with leaving the organization, rather it is because they are happy with ET. This means the management of ET creates a moderate effect on continuance commitment on the employees as compared to ETC.

$\checkmark$ Similar to the finding on affective commitment the new management system has brought a high effect on normative commitment of employees of ET as compared to ETC. this kind of commitment is created due to the fact that the employees think that they are achieving a better training, and assumed they are better paid which let them to feel as they have an obligation at least to return the investment made on them.

$\checkmark \quad$ The average effect of the transformation of the management system of ETC to ET brought a high positive effect on the attitude of the employees with a mean value of

$\checkmark$ Therefore the management of ET brought a high effect on the affective and normative commitments and a moderate effect on the continuance commitments; which means that the employees of ET are highly interested to their company and they feel obliged to stay and serve the organization. However they are not surprised with the costs associated with leaving the organization.

$\checkmark \quad$ Within the achieved commitment there is no difference in commitments of employees associated with their sex, job family they have being a supervisor or supervisee. However, as age increases the level of employee commitment increases. Employees who are Diploma Holders and First Degree Graduates are found to be highly committed than employees with less than diploma and with more than Degree. Employees with Job 
levels $\mathrm{C}$ and $\mathrm{E}$ are more committed than with Job level D. employees with tenure 10.1-20 years are less committed than the tenure below and above the specified year.

$\checkmark \quad$ The variables Employees Relation with Management (ERM) and the Job Security (JS) negative effect affect the employees' commitment. These two variables tells us that even though the average commitment level of ET is found to be high; the management system of ET did not designed a proper employees Relation with Management and Job Security development systems in a manner these two things also add-up other contribution so that the commitment level will go-up from high level to a very high level.

$\checkmark$ The Team Sprit and Work Cooperation (TSWC) and the Work Environment and Condition (WEC) have a moderate effect on the achieved high level of Commitment of the employees of ET to their organization. Though the net effect of these variables is positive and significant; their rate of response to the increment in commitment is not as high as that of COMP and CD variables. Therefore the management of ET is highly expected to improve its management practice in relation to these variables.

$\checkmark \quad$ The Compensation packages (COMP) and the Career Development (CD) programs of the management of ET provide a significant contribution in the improvement of the commitment of Employees of ET. Therefore the management of ET needs a due care at least to keep the managerial practices of these variables at this pace and if possible to improve them.

\section{RECOMMENDATION}

Taking the findings, summary and conclusion drawn from the analyses, the study forwards the following recommendations which mainly triggered to ET.

* The new management of ET let the employees to highly love their job and they greatly develop a sense of mental obligation to continue with ET. Then ET is now right to take this as a one success. However, there is a yellow light which can disturb success. The employees love to their job and their sense of mental obligation to continue with ET is not well connected with awareness of "the costs associated with leaving the organization". The commitment of the employees to further continue work in the organization is not well connected with the inter-employee relationships and associations and other non-transferable funds and investments like allowance and retirement fund or retirement remuneration. This means they still perceive that there is at least a parallel and/or better opportunity in the environment availed to them. Such thinking can have a negative influence on the attitude of the employees not to fully commit themselves to their organization, ET.

* From the analysis of the linkage between employee characteristics and commitment there is one important point that the company should have to be aware of it. In analyzing the linkage between job level and employee commitment of the job levels C, D, and E; the researcher found the employees with job level D is found lesser committed than the others. In analyzing the linkage between tenure and commitment, of the grouped five tenure level which include work years $6 \leq X \leq 10,10<X \leq 15,15<X \leq 20,20<X \leq 25$, and $X>25$ the researchers once again found that the employees with tenure found in the middle i.e. 10.1-20 are identified as less committed than the other extremes. Now these two have a great linkage which can loudly tell us there is a problem around the middle in which the company should have to dig out its cause and solve it.

* The Compensation packages (COMP) and the Career Development (CD) programs of the management of ET provide a significant contribution in the improvement of the commitment of Employees of ET. Therefore the management of ET needs a due care at least to keep the managerial practices of these variables at this pace and if possible to improve them. However the management of ET is advised to assess and redesign its practices with Team Sprit and Work Cooperation (TSWC) and the Work Environment and Condition (WEC) variables and greatly advised to make significant changes with variables Employees Relation with Management (ERM) and the Job Security (JS) so that it will be in a position to reap the full benefit of the management contracting.

\section{Reference}

Abeer, I., Aiman, R., Faisal, T. and Hasnain, R., (2013) 'Impact of Job Satisfaction on Facet of Organizational Commitment' World Applied Sciences Journal 28 (2): 271-277, Department of Management Sciences, COMSATS Institute of Information Technology, Lahore, Pakistan

Ahmadi, A., \&Avajian, Z. (2011). 'Survey relationship between organizational citizenship and organizational commitment in public organization in Iran'.Interdisciplinary journal of contemporary research in business, 3(5), 381-394.

Ahmad, K. Z. \&AbuBakar, R. (2003).'The Association between Training and Organizational Commitment among White-Collar Workers in Malaysia'.InternationalJournal of Training and Development, 7, 166-185

Aubé, C., Rousseau, V. \& Morin, E. M. (2007), 'Perceived organizational support and organizational commitment: the moderating effect of locus of control and work autonomy', Journal of Managerial Psychology, Vol. 22, pp.479-495. 
Business Dictionary, 2013. Retrieved April 2, 2013, from Business Dictionary: http://www.businessdictionary. com/definition/reliability.html

Coakes, S.J. and Steed, L. (2007), "SPSS version 14.0 for Windows", Singapore, John Wiley \& Sons.

Coyle-Shapiro, J. A-M.\& Morrow, P. C. (2006), "Organizational and client commitment among contracted employees", Journal of Vocational Behaviour, Vol. 68, pp.416-431.

Felfe, J., Yan, W., \& Six, B. (2008), "The impact of individual collectivism on commitment and its influence on OCB, turnover, and strain in three countries. 'International Journal of Cross-Cultural Management, Vol. 8, pp.211-237.

Feryal, K. \&Sohail, Z., (2013), “An Empirical Study of Affective Commitment across Demographic groups in the Banking Sector of Pakistan" Pakistan Journal of Commerce and Social Sciences, Vol. 7 (3), 555-563

Hair, J.F., Black, B., Babin, B., Anderson, R.E. and Tatham, R.L., (2006), "Multivariate Data Analysis”, Sixth Edition, NJ, Prentice Hall.

Iqbal, A. (2010). "An empirical assessment of demographic factors, organizational ranks and organizational commitment".International Journal Of Business Management, 5,16-27.

Jayasingam, S., \& Yong, J. R. (2013). "Affective commitment among knowledge workers: the role of pay satisfaction and organization career management." The InternationalJournal of Human Resource Management, 24(20), 1-18.

Lin, C. and Wang, W. (2012)."The Relationship between Affective and Continuance Organizational Commitment."Journal of Asian Business Strategy, Vol. 2, No. 5, pp. 89-94

Liden, R. C., Wayne, S. J., Kraimer, M. L. \&Sparrowe, R. T. (2003), "The dual commitments of contingent workers: an examination of contingents' commitment to the agency and the organization", Journal of Organizational Behaviour, Vol. 24, pp.609-635.

Murphy, K. and W. Balzer, 1989."Rate Error and Rating Accuracy.”Journal of Applied Psychology, 71(4): 61924.

Meyer, J.P., Stanley, D., Hescovitch, L., \&Toplnytsky, L. (2002). "Affective, continuanceand normative commitment to the organization: A meta-analysis of antecedents,correlates and consequences." Journal of Vocational Behavior, 61, 20-52.

Meyer, J.P. \& Allen, J.J. (1997). “Commitment in the Workplace: Theory, Research and Application.” Thousand Oaks, CA. Saga Publications.

Muhammad, A., Yan, J., Nazar, H., and Zafar-uz-Zaman, A. (2014); "Factors Affecting Organizational Commitment Among Bank Officers In Pakistan",IOSR Journal of Business and Management, Volume 16, PP 18-24

Natarajan, N. \& Nagar, D. (2011)."Effects of Service Tenure and Nature of Occupation on organizational Commitment and Job satisfaction."Journal ofManagement Research, 11, 59-64.

Pathardikar, A.D. \&Sahu, S. (2011). "Implications of the Organization Cultural Antecedents on Organizational Commitment: A Study in Indian Public Sector Units." Global Business Review. 12(3),431-446.

Prowle, M. (2006), "The Role of The Private Finance Initiative in the Delivery of Health Services in the UK. Technical Approach Paper.HLSP Institute,London, UK.

Reichers, A. (1985). A Review and Re-Conceptualization of Organizational Commitment. Academy of Management Review, 11(5): 465-476.

Rhoades, L. \&Eisenberger, R. (2002), "Perceived organization support: a review of the literature", Journal of Applied Psychology, Vol.87, pp.698-714.

Sarah, B., Jolian, M., Robert, M., \& Karl, T. (2011)."Workplace performance, worker commitment and loyalty."Forschungs institute zurZukunft der Arbeit Institute for the Study of Labor, IZA Discussion Paper No. 5447.

Shore, L. M. \& Wayne, S. J. (1993), “Commitment and employee behaviour: comparison of affective commitment and continuance commitment with perceived organizational support", Journal of Applied Psychology, Vol.78, pp.774-780.

Su,S., Baird, K. \& Blair, B. (2009). "Employee Organizational commitment: the influence of cultural and organizational factors in the Australian manufacturing industry." TheInternational Journal of Human Resource Management.20(12), 2494-2516.

Thomas, D.S., 2011. "Addiction in Internet Chatting: An Empirical Study Using Modified Technology Acceptance Model”. Interdisciplinary Journal of Contemporary Research in Business, 3(4): 287-298.

Tung, N., Khuong, N. and Phuong, V. (2014) "Factors affecting Organizational commitment." Journal of Advanced Management Science Vol. 2, No. 1,

Wang, C., Indridasson, T and Saunders MNK (2010).“Affective and continuance commitment inpublic private partnership."Employee Relations 32.4 396-417 